\title{
Gender differences in the impact of family background on leaving the parental home
}

\author{
Marjolein Blaauboer • Clara H. Mulder
}

Received: 7 October 2008/Accepted: 19 June 2009/Published online: 26 November 2009

(C) The Author(s) 2009. This article is published with open access at Springerlink.com

\begin{abstract}
We address the question to what extent characteristics of the family of origin influence the timing of leaving the parental home and to what extent these effects differ between men and women. We use data from the Netherlands Kinship Panel Study to examine the effects of parental resources, atmosphere in the family of origin and family structure on leaving home to live without a partner and leaving home to live with a partner. The results indicate that a pleasant atmosphere in the parental home decreases the risk of leaving home and living in stepfamilies or single-parent families increases this risk. The availability of parental resources leads to a decreased risk of leaving home at young ages, but an increased risk at later ages. Many of these effects are found for both men and women and for both pathways out of the home. Furthermore, we find evidence that women are affected more strongly by family background characteristics than men are.
\end{abstract}

Keywords Family structure - Gender differences · Leaving the parental home * The Netherlands

\section{Introduction}

Leaving the parental home is one of the first major transitions in the life course: a step in the transition to adulthood with important consequences for both parents and the child (Goldscheider and Goldscheider 1999; Rusconi 2004; Mulder and Hooimeijer 2002). The timing of this transition is influenced by determinants such as developmental readiness and societal norms, individual resources, opportunity structures (for instance the economic and housing market conditions) and family background characteristics (Mulder 2009). In this article, we focus on the influence of a broad range of family background characteristics on the timing of leaving the parental home. Moreover, literature suggests that life course

\footnotetext{
M. Blaauboer $(\bowtie) \cdot$ C. H. Mulder

Department of Geography, Planning and International Development Studies, Universiteit van Amsterdam, Nieuwe Prinsengracht 130, 1018 VZ Amsterdam, The Netherlands

e-mail: m.blaauboer@uva.nl
} 
trajectories, and specifically those related to the transition to adulthood, are very different for young men and young women (Canada-Vicinay 2005; Andres and Adamuti-Trache 2008). We therefore also use a gender approach in this article by examining the differences in the effects of family background characteristics on the timing of leaving the parental home of men and women.

Several studies have addressed the influence of parental resources on leaving the parental home (Aassve et al. 2002; Avery et al. 1992; Mulder et al. 2002; Whittington and Peters 1996). These studies usually find that parents' economic resources lead to a diminished likelihood of leaving home at young ages of the child, but facilitate it once the child gets older. Other studies have drawn the attention to the influence of family structure. The strong increase in divorce rates and in the number of households that do not consist of two natural parents and children has led to dramatic changes in the family structure in which young adults grow up. More and more children experience a parental divorce, grow up in single-parent families or live with a stepfather or stepmother for part of their childhood (Kiernan 1992). This influences both the nature of the relationships between (step)parents and (step)children as well as the amount of resources that a family has available for their children (Aquilino 1991; Goldscheider and Goldscheider 1999; Fischer 2004). Previous research on the influence of family structure has shown a strong increase in the risk of home leaving at younger ages for those who live with stepparents or grow up in single-parent families (Mitchell et al. 1989; Cooney and Mortimer 1999). Still other studies have examined the impact of the family atmosphere in the parental home, and concluded that young adults are less likely to leave from a pleasant parental family (see Mitchell et al. 1989; De Jong Gierveld et al. 1991; Aquilino 1997).

In many studies on leaving the parental home it is acknowledged that the process of leaving home differs between men and women. In several studies, therefore, men and women are studied separately. The results of these studies suggest that there are gender differences in the influence of parental resources or characteristics of the family of origin (Buck and Scott 1993; Goldscheider and Goldscheider 1999; Mulder and Hooimeijer 2002). Women might be influenced more by parental resources such as occupational status (Mulder and Hooimeijer 2002; Aassve et al. 2002) and seem to be affected more by the family atmosphere and changes in the family structure than men are (Mitchell et al. 1989; Buck and Scott 1993). Young men seem to develop different relationships with their single mothers and stepfathers and experience conflicts and tensions in different situations and to a different extent than women (Aquilino 1991).

However, even though separate analyses for men and women are rather common, very few studies provide us with analyses that show which effects of family background differ significantly between men and women and to what extent. Moreover, in most research either the influence of parental resources or the effect of aspects of the family atmosphere and structure are studied, but not both at the same time. In this paper we present a thorough examination of gender differences in the effect of parental resources, family atmosphere and family structure. We test whether the impact of family background on men's and women's likelihood of leaving the parental home differs and on which aspects. We consider two pathways out of the parental home: leaving to live without a partner and leaving to live with a partner. The research question we address is:

To what extent do characteristics of the family of origin influence the timing of the transition of leaving the parental home for the first time to live without a partner or to live with a partner, and to what extent do these effects differ between men and women? 
We use recent data from the first wave of the Netherlands Kinship Panel Study (NKPS, Dykstra et al. 2005). These data include an extensive measurement of family structure, parental resources and information about the atmosphere in the family. The dataset is analyzed using event history techniques.

\section{Theoretical framework}

Theoretical explanations for the differences in the timing of leaving the parental home between different (groups of) individuals often draw from a family life course perspective. The family life course perspective pays attention to the interaction between demographic, social and cultural factors that shape family relations and emphasizes the changes in roles and positions in the family and household domain of individuals when they experience life course transitions (Elder 1994; Hareven 1994; Elder et al. 2003; MacMillan and Copher 2005). The fact that family members lead 'linked lives' (Elder 1994) also implies that those changing roles both influence and are influenced by other persons connected to the individual experiencing the transition (MacMillan and Copher 2005; Aquilino 1997; Bucx et al. 2008). Moreover, life course theories stress the importance of previous life course experiences: they shape and influence decisions and pathways later in the life course (Hareven 1994). Leaving the parental home is often one of the first life course events that marks the transition to adulthood. It thus coincides with major changes in the roles and functions within the family of origin. The decision of leaving the parental home is therefore often not made solely or independently by the adolescent, but is likely to be influenced by characteristics of the household in which they grew up. From a family life course perspective, the family background, including both the interactions between family members and the shared previous life course events, is expected to influence the decision to leave the parental home profoundly.

Theories on intergenerational transmission also add to the explanation of differences in the timing of leaving the parental home. Parents influence the lives of their children both through direct transmission of resources and through socialization: the transmission of values and preferences (Blau and Duncan 1967; Avery et al. 1992; Goldscheider and Goldscheider 1999). As a result, parents with different amounts of resources will differ in the support they can offer their children, and parents with different norms and values will stimulate or discourage certain decisions of their children. As Furstenberg (2008) argues, the transition to adulthood is strongly shaped by social class. During early adulthood, people from advantaged and disadvantaged family backgrounds are likely to take divergent paths (Furstenberg 2008). The timing of the transition to leaving the parental home is thus also likely to be influenced by material and non-material parental resources and values because they frame the opportunities and constraints that young people face when wanting to leave the parental home.

Using the theoretical frameworks on the family life course and intergenerational transmission of resources and values, we divide the discussion of family background characteristics into (1) parental resources and (2) family structure, atmosphere and values of the family of origin. Furthermore, we devote attention to other characteristics of the young adult we have to account for: age, level of education, cohort differences and immigrant status.

It is important to acknowledge that different motives can underlie young adults' home leaving. For example, leaving home to get married and leaving home for college have repeatedly proven to be very different processes with different causes and effects. It is 
therefore important to distinguish between motives for leaving the parental home (Goldscheider and Goldscheider 1999; Lahelma and Gordon 2003; Rusconi 2004). Like in much previous research (for example Buck and Scott 1993), we distinguish between leaving home to live without a partner (including living alone or with roommates) and leaving home for union formation (including both marriage and cohabitation). Leaving home to live without a partner may include leaving for educational reasons, for a job or because of a desire for independence and autonomy.

\subsection{Parental resources}

Resources that parents can transmit to their children have an important influence on young adults' opportunities for leaving their parental home. The more parental resources are available to young adults, the more likely it is that they can realize their preferences and overcome constraints. De Jong Gierveld et al. (1991) distinguish between material and non-material transferable resources. Material transferable resources include forms of economic capital, whereas cultural capital, such as the level of education, is a non-material transferable resource (De Jong Gierveld et al. 1991).

There is a strong intergenerational transmission of the level of education from parents to their children. Children whose parents have attained a higher level of education often attend higher education themselves as well (Blau and Duncan 1967). Moreover, their parents are more likely than others to have a history of migration for education or work, which may serve as an example to the young adults. They will therefore leave home more frequently in order to attend college or university than children of less well educated parents. Parents who have attained a higher level of education tend to highly value openness to innovation and autonomy. Through socialization, these cultural values will be transmitted to their children. They will thus be more likely to leave home for independence and autonomy than children of less well educated parents (De Jong Gierveld et al. 1991). We thus expect a positive effect of the level of education of the parents on leaving home to live without a partner, whereas, because of social norms on independence of the parents, there might be a negative effect on leaving home to live with a partner.

The socio-economic status of the parents has often been proven to have a substantial effect on the transition to leaving the parental home (Avery et al. 1992; Mulder et al. 2002). A high amount of socio-economic parental resources can have two contrasting effects: it can stimulate leaving home because it can help overcome constraints, but it can also create a comfortable home situation-a so-called feathered nest-in which young adults prefer to stay (Avery et al. 1992; Goldscheider and Goldscheider 1999). The effect of parental resources is likely to change when a person gets older. At younger ages, a good financial home situation might lead to a longer stay at the parental home, while with increasing age, parental resources can help young adults to find comfortable housing when they decide they want to leave the parental home (Avery et al. 1992). For the Netherlands, De Jong Gierveld et al. (1991) and Mulder et al. (2002) found a positive effect of father's socioeconomic status for leaving home to live without a partner. Mulder and Hooimeijer (2002) suggest that those who leave home to live without a partner might be more in need of parental support. For both pathways out of home, we expect a negative effect of the socioeconomic status of the parents at a young age of the child, because of a comfortable home situation. With an increasing age however, young adults may want to start living independently, despite the benefits living with their parents might have. We thus expect that at later ages, a higher socio-economic status of the parents increases the chances of leaving 
home. This might be especially the case for leaving home to live without a partner because of a greater need for financial help of the parents.

Homeownership of the parents often coincides with a good financial situation of the household. Furthermore, homeowners can use equity from their homes to help their children financially or to guarantee their mortgage. Parental homeownership can thus be considered as a socio-economic resource. This may lead to better opportunities for young adults to leave the parental home although the feathered nest hypothesis may also apply. For Germany and the United States, Mulder et al. (2002) found a positive effect of parental home ownership on leaving home to live with a partner, but a negative effect on leaving home to live without a partner. It is possible that, after accounting for the parents' socioeconomic status, their homeownership mainly indicates a feathered nest for those who might otherwise leave home to live without a partner in shared or low-quality accommodation, but for those planning to form a union, the available resources enable young couples to afford a suitable, possibly owner-occupied home. We therefore expect a positive effect of parental homeownership on leaving for reasons of marriage or cohabitation, and a negative effect on leaving home to live without a partner.

\subsubsection{Gender differences in the effect of parental resources}

Women might be more strongly influenced by their family background than men because their behavior and decisions are generally more closely monitored and supervised by the parents. In other words, parents keep a closer eye on their daughters than on their sons (Mitchell 2004). Women also tend to have closer relationships with their parents than men (Rossi and Rossi 1990). Parents might therefore be more willing to support daughters than sons. We thus expect that the effects of parental resources are greater for females than for males. In previous research, however, contrasting results have been found in relation to gender differences in the effect of parental resources. For the Netherlands, Mulder et al. (2002) found that women are more likely to be influenced by their fathers' level of education than men are. However, men were found to be more affected by their fathers' socio-economic status than women were (Mulder et al. 2002; Mulder and Hooimeijer 2002). A positive effect of parental income only for males was found by Buck and Scott (1993) for the United States and Aassve et al. (2002) for several European countries. Unfortunately, no theoretical explanations are given for these results, but it is possible that, in contrast to our hypothesis, parents particularly help sons because they expect sons to take up the provider role in their future families.

\subsection{Family structure, atmosphere and values in the parental home}

Non-material characteristics of the family of origin can strongly affect the lives of young adults. Firstly because the atmosphere in the family and changes in the family structure shape family relations. Secondly because non-material characteristics such as values and preferences of parents are transmitted to their children, thus influencing their preferences and decisions (De Jong Gierveld et al. 1991).

De Jong Gierveld et al. (1991) argue that intra-familial care and understanding are important non-material resources that affect leaving home. In general, one could expect that young adults are more likely to stay at home when their relationship with their family members is good, when they feel pleasant being at home and when the family atmosphere is warm and caring (De Jong Gierveld et al. 1991). This family atmosphere is strongly influenced by the quality of the relationship between the parents. When parents often argue 
with each other or have quarrels, the ambience at home will be less pleasant. Young adults may flee from their parental home earlier when their parents have a bad relationship. It has been argued that a good home atmosphere gives young adults time to wait with leaving home until they are ready for independence or that it prevents them from getting involved in early, high risk marriages (Goldscheider and Goldscheider 1999). It has also been argued that the fact that children of divorced parents leave home earlier might partly be caused by their having experienced higher levels of conflicts within the parental home (Kiernan 1992). The hypothesis is that the higher the quality of the relationship between the parents, the longer young adults will stay at home, for both pathways out of the home.

The availability of space and privacy in the parental home also affects the extent to which young adults feel comfortable at home. Because in larger families there might be a lack of space or privacy and because parents with more children have to divide their attention between them, young adults with siblings may leave home earlier compared to those without any siblings (Mitchell et al. 1989; Aquilino 1991; De Jong Gierveld et al. 1991). On the other hand, having more siblings implies that parents have to divide their resources among more children, which decreases the amount available per child. This could delay the timing of leaving the parental home (Rusconi 2004). The hypotheses that can be derived from these ideas are competing: having more siblings might either increase or decrease the likelihood of leaving home at a given point in time.

The family structure and the changes in it during childhood are likely to affect the family atmosphere. Changes in the family structure during childhood such as a divorce and the formation of a non-standard family (not containing both natural parents) to a great extent influence relationships between family members, especially between (step)parents and children (Mitchell et al. 1989). Single-parent families often also have fewer resources available than two-parent families. Stepfamilies are more likely to have problems in relationships among family members, such as problems with and confusion about authority between the stepparent and stepchild (Mitchell et al. 1989; Aquilino 1991). Therefore, non-standard family structures tend to increase the likelihood of leaving home by pushing young adults out of the household because of tensions or conflict. In several previous studies strong evidence was found that individuals living in single-parent families and stepfamilies during childhood have a much higher risk of leaving the parental home than individuals growing up with both natural parents (Mitchell et al. 1989; Aquilino 1991; Buck and Scott 1993; Cooney and Mortimer 1999). The strongest effects are often found for leaving home to live without a partner, although leaving home for union formation is also speeded up (Aquilino 1991). We expect that living in nonstandard family structures will lead to a higher risk of leaving the parental home for both pathways out of the home.

Religiosity can be seen as a value that strengthens family-centered orientations and as a form of traditionalism (Mitchell 2004). Parents are likely to transfer their religious values to their children, and therefore influence their home-leaving motives and decisions (De Jong Gierveld et al. 1991). Religious parents and their children might value traditional home-leaving patterns more highly and thus have a preference for leaving home for marriage and perceive leaving home to live without a partner as less appropriate. Research has indeed shown that religiosity of the parents leads to a higher risk of leaving home for reasons of marriage and to a lower risk of leaving home for other reasons (Mitchell 2004; Rusconi 2004). We expect parents being religious to lead to a smaller likelihood of leaving home to live without a partner. The opposite result is expected for leaving home to live with a partner. 


\subsubsection{Gender differences in the effect of family structure, atmosphere and values}

As we argued before, characteristics of the family of origin may influence women to a greater extent than men because parents may keep a closer eye on their daughters or feel more need to help their daughters than their sons. Women often also value having a good relationship with their family members more than men because they perceive themselves as (future) kin keepers in a family (Rossi and Rossi 1990). Other life course transitions, such as leaving the educational system and entering the labor market, are also affected differently by family structures for men than for women. It has been suggested that young women seem to respond more actively to difficulties within the family, such as a parental divorce, while young men adopt a passive approach (Canada-Vicinay 2005). Previous research on home leaving for the United States shows that women are affected more strongly by conflicts and tensions in the parental home than men are (Aquilino 1991; Buck and Scott 1993). Kiernan (1992) found similar results for the UK. Cooney and Mortimer (1999) found that a higher quality of the relationship with the parents only leads to a lower risk of leaving the parental home for girls. Both Buck and Scott (1993, for the United States) and Rusconi (2004, for West Germany and Italy) found an effect of family size for women's chances of leaving home for marriage or family formation but not for men. We thus expect that the effects of the quality of the parental relationship and the number of siblings will be greater for females than for males.

Single-parent families often consist of a mother with one or more children. This family structure, in which a male parent is absent, can have a different effect on young men and women. Women are more likely to develop a close relationship with their mothers when their father is absent. Men, on the other hand, might miss a father figure during childhood and experience more conflicts with their mother (Aquilino 1991). The effect of living in a single-parent family on leaving home is thus likely to be greater for males than for females. The opposite holds for living in stepfamilies, which often consist of a biological mother and a stepfather. Young men seem to profit from the presence of a man in the household, whereas young women often experience tensions and conflicts with their stepfathers (Aquilino 1991; Buck and Scott 1993; Cooney and Mortimer 1999). The effect of living in a stepfamily might thus be stronger for females than for males. For other family structures, Aquilino (1991) found that living in an adoption family resembles living in a stepfamily. We thus expect a stronger effect of living in other family structures, which in our study mainly includes adoption, for women.

Since religious parents often hold more traditional values towards family life and life course decisions, leaving home to live without a partner might be something they like seeing neither their sons nor their daughters do. Being more traditional, however, may also indicate having traditional gender role attitudes implying holding different norms for sons and daughters. Religious parents might object more strongly to their daughters living without a partner than their sons (Mitchell 2004; Rusconi 2004). We thus expect a stronger negative effect of religiosity on leaving home to live without a partner for women than for men. Leaving home to live with a partner might be the preferred pathway out of the home for both sons and daughters. We therefore have no reason for expecting differences in the effect of religiosity between men's and women's likelihood of leaving home to live with a partner.

\subsection{Individual characteristics}

Previous research has consistently shown a strong age differentiation in leaving the parental home in Western countries, which we obviously have to account for. Leaving 
home to live without a partner is concentrated in the younger ages (up to 20), due to the fact that in the Netherlands people who leave home to live without a partner often do this for educational reasons. Leaving home to live with a partner takes place at slightly older ages. Women leave home at younger ages than men, particularly for living with a partner (Billari and Liefbroer 2007).

Educational enrolment and the level of education attained have a strong impact on the transition to leaving the parental home. In the Netherlands, young adults often leave home to live in student apartments when they enroll in higher vocational or university education, which is feasible for a considerable number of students because of state grants for students in higher education. Research also shows that a high educational degree has a positive effect on leaving the parental home to live without a partner (Mulder and Hooimeijer 2002). In contrast, there are normative expectations that being a student and being married or cohabiting are incompatible so that young adults wait with union formation until they have left education (Blossfeld and Huinink 1991). The incompatibility of being a student and forming a union seems to hold specifically for women. A higher completed level of education often indicates a high degree of non-traditionalism and highly valuing independence, possibly leading to postponement of partnership formation and late marriage. At the same time, those who have completed higher education have a greater income potential and usually higher actual incomes, and are therefore in a stronger position to form partnerships and families. In a society as the Netherlands where the male breadwinner has not yet disappeared, this might imply that particularly highly educated men do not differ that much from less well educated men in their chances of leaving home to live with a partner (compare Aassve et al. 2002, who found a negative effect of low education on leaving home for males but not for females).

Like many other Western countries, the Netherlands has witnessed a decrease in the age of leaving home among cohorts born in the early twentieth century up to those born in the 1960s, whereas later cohorts show a slightly later timing. Furthermore, there has been an increase in the likelihood to leave home to live without a partner, whereas before World War II, marriage was the standard route out of the parental home (Iedema et al. 1997).

Little is known about the differences in leaving home between migrants and native Dutch in the context of the Netherlands. A small-scale study by Bolt (2002) suggests that young Turks and Moroccans - two of the largest immigrant groups in the Netherlands-are unlikely to leave the parental home to live without a partner. And also, that a substantial share of particularly young Turkish couples live in the husband's parents' home for a while before forming their own households. De Valk and Billari (2007) show that Moroccans are somewhat more likely to co-reside with their parents than native Dutch. Native Dutch seem to value autonomy more strongly than young adults from other ethnic backgrounds, which results in a somewhat earlier home leaving for native Dutch. Women of ethnic minority groups also tend to prefer younger ages for marriage and entry into motherhood (De Valk and Liefbroer 2007). We might thus expect that native Dutch leave home earlier and might be more likely to leave home to live without a partner, while non-Western immigrants are more likely to leave home to live with a partner.

\section{Data and methods}

The data come from the main sample of the first wave of the Netherlands Kinship Panel Study (NKPS; Dykstra et al. 2005), which was conducted in 2002-2004. The main sample of this dataset contains data about 8,161 respondents, all residents of the Netherlands and 
aged 18-79. The dataset includes information about a broad range of socio-economic, demographic and family characteristics. Respondents were interviewed using CAPI questionnaires (Computer Aided Personal Interviewing) and filled out a self-completion questionnaire with additional questions. Information about the family of origin and the parents was obtained through retrospective questions. The overall response rate was $45 \%$. This is comparable with other Dutch large-scale surveys (see Dykstra et al. 2005 for a detailed discussion of the response rate and sample representation). We selected all respondents born before 1981, who were at least 22 years old at the time of interview. At this age over $65 \%$ of the respondents had already left home. After dropping cases with missing values, mainly on parental level of education and on the quality of the relationship between the parents (3.9\% cases with missings of the 7,734 in the selected birth cohorts who had not left home before age 16), 7,429 respondents remained.

The dependent variable is a measure of whether the transition to leaving the parental home for the first time took place in a particular year. The question asked was: In which year did you leave home to go and live on your own? Based on the questions when the respondent started living together with a partner (either unmarried cohabitation or cohabitation within marriage) or got married for the first time, we constructed two outcomes. If the year in which the respondent has left the parental home was equal to the year in which the respondent started cohabitation or got married, the outcome was coded as 'leaving home to live with a partner'. In other cases, the outcome was coded as 'leaving home to live without a partner'. Process time starts at age 16 and ends at age 35 because this event happening before or after that age is considered to be out of the ordinary and needs a more in-depth way of studying. Cases were censored at the time of interview or at age 35 when the transition had not been made by that age.

Fathers' socio-economic status was measured using a question about the occupation of the father when the respondent was aged 15. The occupations were coded using the International socio-economic index (ISEI) (Ganzeboom et al. 1992) which runs from 10 to 80 . It was divided by 10 to obtain better readable parameters. Missing values were imputed with the mean value, and a dummy variable for the missing values was added in the analyses. Additionally, an interaction variable of fathers' socio-economic status with age was created. Unlike for the main effect of age, we did not use age groups but a continuous measurement of age for this interaction term to reduce the number of degrees of freedom. For the level of education of the parents, the education of the parent with the highest level was taken into account.

The family atmosphere at home was approximated by a measurement of the quality of the parental relationship when the respondent was 15 years old. This parental relationship quality was measured using five items about how often parents were having arguments with each other or even lived separated for a while. The five items have a Cronbach's alpha of .78, which indicates a good internal consistency. The variable was created by taking the mean value on these items and dividing the variable into three categories using the 33rd and 67th percentiles: low, medium and high quality of the relationship. We used this categorical division because the scores on the variable are skewed towards the higher values, implying that respondents retrospectively tend to consider their parents' relationship of a rather good quality. It is unclear to what extent this is caused by a memory bias. For respondents whose parents never lived together, no information is available about the quality of the parental relationship. Therefore, an extra category was added to the variable to account for this lack of information.

We constructed a time-varying covariate for family structure, using information about all different family situations and the timing of the changes from one situation to another 
that a respondent has experienced from birth until the moment of leaving the parental home. The first family structure indicates a family situation where the respondent is living with both natural parents. The second structure indicates living with only the mother or only the father (single-parent structure). The third structure indicates a stepfamily: the respondent is living with one natural parent and a stepparent. The last category contains all other family structures such as living with other family members or in an adoption family.

Religiosity of the parents was measured using the respondent's report about whether his or her parents counted themselves as belonging to a particular religion when the respondent was aged 15. This question was taken from the self-completion questionnaire. A separate category 'unknown' was used for those who did not fill out that questionnaire or did not answer this specific question.

Since only the completed level of education of the respondent at the time of interview is available, we had to rely on this information in order to develop a time-varying covariate that combines both enrolment and level of education. First we recoded the different levels of education into the years of education it normally takes to reach this level after finishing primary school: 7 years for secondary vocational education (MBO), 9 years for higher vocational education (HBO), 11 years for a university study and 15 years for post-graduation education. By adding 12 years (since children in the Netherlands on average leave primary school at that age), we have a proxy for the age of completing education. A timevarying covariate was created for being in or out of education, combined with the level of education completed. Three categories were formed for those no longer in education, namely up to lower vocational degree, middle or higher secondary or middle vocational degree, and higher vocational or university degree. To control for possible cultural differences, we included a dummy variable for being a non-Western immigrant or secondgeneration non-Western immigrant. This variable was coded 1 when the respondent or at least one of the parents was born in a non-Western country. Table 1 shows descriptive statistics of the covariates.

Event history analysis techniques were used. Since the dataset provides only annual information, discrete time analysis was the best option (Allison 1982). We therefore used multinomial logistic regression analysis of person-years, where not having left the parental home (yet) is the base outcome. Leaving the parental home to live without a partner and leaving home to live with a partner are the outcomes of interest, analyzed using a competing risk approach. Since we were interested in the differences between males and females, we estimated the models for females and males separately. To test whether the odds ratios in the model for men and the model for women are significantly different, we use seemingly unrelated estimations of the two models (Clogg et al. 1995; Weesie 1999). With this procedure, the coefficients and standard errors of the two models are estimated simultaneously. The coefficients obtained from this simultaneous estimation are the same as those obtained from separate estimations, but the standard errors are robust, which allows comparing the coefficients across the estimators. Using this procedure, we are able to compare the parameters from the models for men and for women. This enables us to examine whether certain independent variables have a greater effect for men or for women.

\section{Results}

The results of the multinomial logistic regression analyses are presented in Table 2. Since we are interested in comparing females and males, we arranged the columns in the table not by model (a model for females and a model for males) but by route out of the parental 
Table 1 Descriptive statistics in the year of leaving home or at censoring $(N=7,429,50,516$ personyears)

\begin{tabular}{|c|c|c|}
\hline & $N$ & $\%$ \\
\hline \multicolumn{3}{|l|}{ Reason for leaving home } \\
\hline Did not leave home & 191 & 2.6 \\
\hline Without a partner & 3,903 & 52.5 \\
\hline With a partner & 3,335 & 44.9 \\
\hline \multicolumn{3}{|l|}{ Sex } \\
\hline Male & 3,109 & 41.8 \\
\hline Female & 4,320 & 58.2 \\
\hline \multicolumn{3}{|l|}{ Parental level of education } \\
\hline Up to lower vocational & 3,573 & 48.1 \\
\hline Middle or higher secondary or middle vocational & 2,451 & 33.0 \\
\hline Higher vocational or university & 1,405 & 18.9 \\
\hline Fathers' socio-economic status missing & 95 & 1.3 \\
\hline \multicolumn{3}{|l|}{ Parents homeowner at age 15} \\
\hline No & 3,542 & 47.7 \\
\hline Yes & 3,887 & 52.3 \\
\hline \multicolumn{3}{|l|}{ Quality parental relationship at age 15} \\
\hline Low quality & 2,093 & 28.2 \\
\hline Medium quality & 2,903 & 39.1 \\
\hline High quality & 2,349 & 31.6 \\
\hline Parents never lived together & 84 & 1.1 \\
\hline \multicolumn{3}{|l|}{ Number of siblings } \\
\hline No siblings & 347 & 4.7 \\
\hline One or two siblings & 3,478 & 46.8 \\
\hline Three or four siblings & 1,954 & 26.3 \\
\hline Five or more siblings & 1,650 & 22.2 \\
\hline \multicolumn{3}{|l|}{ Family structure } \\
\hline Both natural parents together & 6,369 & 85.7 \\
\hline Single parent & 677 & 9.1 \\
\hline Stepfamily & 205 & 2.8 \\
\hline Other & 178 & 2.4 \\
\hline \multicolumn{3}{|l|}{ Religiosity parents at age 15} \\
\hline Not religious & 1,110 & 14.9 \\
\hline Religious & 5,331 & 71.8 \\
\hline Unknown & 988 & 13.3 \\
\hline \multicolumn{3}{|l|}{ Level of education completed } \\
\hline In education & 2,300 & 31.0 \\
\hline Up to lower vocational & 2,502 & 33.7 \\
\hline Middle or higher secondary or middle vocational & 1,795 & 24.2 \\
\hline Higher vocational or university & 832 & 11.2 \\
\hline \multicolumn{3}{|l|}{ Cohort } \\
\hline $1923-1939$ & 1,274 & 17.1 \\
\hline 1940-1949 & 1,307 & 17.6 \\
\hline 1950-1959 & 1,595 & 21.5 \\
\hline
\end{tabular}


Table 1 continued

\begin{tabular}{|c|c|c|}
\hline & $N$ & $\%$ \\
\hline 1960-1969 & \multirow[t]{2}{*}{1,878} & 25.3 \\
\hline $1970-1980$ & & \\
\hline \multicolumn{3}{|l|}{ Immigrant or second generation immigrant } \\
\hline No & 7,108 & 95.7 \\
\hline \multirow[t]{2}{*}{ Yes } & 321 & 4.3 \\
\hline & Mean & $\mathrm{SD}$ \\
\hline Fathers' socio-economic status at age 15 & 4.492 & 1.52386 \\
\hline Age $\times$ fathers' socio-economic status & 30.545 & 19.20471 \\
\hline
\end{tabular}

Source: NKPS

home. Consequently, the odds ratios of leaving home to live without a partner for females are next to the odds ratios of leaving home to live without a partner for males, and the odds ratios of leaving home to live with a partner for females and males are also side by side. The third and sixth columns show whether the parameters from the models for females and the models for males differ from each other significantly.

\subsection{The impact of parental resources}

As expected, for both men and women a higher level of education of the parents leads to a greater likelihood of leaving home to live without a partner in a given year. For those females and males who have parents with the highest level of education, the risk is estimated to be $65 \%$ and $93 \%$ higher than for those with parents with up to lower vocational education. The effect of parental level of education on leaving home to live with a partner is less strong: an effect is only found for males. Contrary to what we expected, this effect is positive. A higher socio-economic status of the father leads to a lower risk of leaving the parental home for both men and women at young ages along both pathways. The effect seems stronger for leaving home to live with a partner. The interaction effect with age is positive, which indicates that with an increasing age, the negative effect of fathers' socio-economic status becomes less negative until at a certain age it becomes positive. For leaving home to live without a partner, the turning point is estimated to lie at the age of 18.6, both for men and for women. For leaving home to live with a partner, the turning points are estimated to lie at the age of 22.3 for women and 25.7 for men. After this age, a higher socio-economic status of the father leads to an increased risk of leaving home. This is in line with our expectations that parental resources stimulate home leaving after a certain age, while before that it gives young adults a reason to stay at home. Parental homeownership only significantly affects women's likelihood of leaving home to live without a partner. Opposite to what we expected and to what we found for the socioeconomic status of the father, this effect is positive, indicating that women leave home earlier to live without a partner when their parents are homeowners. Possibly, the economic resource effect of homeownership is stronger than the feathered-nest effect.

We expected a stronger effect of parental resources for women than for men. This expectation is not confirmed for the level of education of the parents. The unexpected positive effect of parental education on the likelihood of leaving home to live with a 
Table 2 Multinomial odds ratios for the transition to leaving the parental home (separate models for females and males)

\begin{tabular}{|c|c|c|c|c|c|c|}
\hline & \multicolumn{3}{|c|}{ Without a partner } & \multicolumn{3}{|c|}{ With partner } \\
\hline & Females & Males & Diff. & Females & Males & Diff. \\
\hline Constant & $0.05^{* * *}$ & $0.05^{* * * *}$ & & $0.03^{* * *}$ & $0.01 * * *$ & $* * *$ \\
\hline \multicolumn{7}{|c|}{ Parental level of education (ref. up to lower vocational) } \\
\hline $\begin{array}{l}\text { Middle or higher secondary or middle } \\
\text { vocational }\end{array}$ & $1.18^{* * *}$ & $1.31^{* * * *}$ & & 1.00 & $1.23 * * *$ & $* *$ \\
\hline Higher vocational or university & $1.65^{* * * *}$ & $1.93^{* * *}$ & & 0.97 & 0.96 & \\
\hline Fathers' socio-economic status at age 15 & $0.89^{* * *}$ & $0.91 * * *$ & & $0.74 * * *$ & $0.75 * * *$ & \\
\hline Age $\times$ fathers' socio-economic status & $1.05^{* * *}$ & $1.04 * * *$ & $* *$ & $1.05^{* * *}$ & $1.03 * * *$ & $* * *$ \\
\hline Fathers' socio-economic status missing & 0.92 & $1.49 *$ & & 1.13 & 1.26 & \\
\hline Parents homeowner at age 15 & $1.09 *$ & 1.02 & & 0.99 & 0.91 & \\
\hline \multicolumn{7}{|l|}{ Quality parental relationship at age 15 (ref. low) } \\
\hline Medium quality & $0.78^{* * * *}$ & $0.76^{* * * *}$ & & $0.88^{*}$ & $0.78^{* * * *}$ & \\
\hline High quality & $0.65^{* * *}$ & $0.77^{* * * *}$ & $*$ & $0.86^{* *}$ & $0.80 * * *$ & \\
\hline Parents never lived together & 0.72 & 1.02 & & $0.61 *$ & 0.77 & \\
\hline \multicolumn{7}{|l|}{ Number of siblings (ref. no siblings) } \\
\hline One or two siblings & 1.21 & 1.14 & & 0.97 & 1.18 & \\
\hline Three or four siblings & $1.29 * *$ & 0.99 & & 0.96 & $1.31^{*}$ & \\
\hline Five or more siblings & 1.22 & 1.23 & & 0.96 & $1.31^{*}$ & \\
\hline \multicolumn{7}{|l|}{ Family structure (ref. both natural parents) } \\
\hline Single parent & $1.29 * * *$ & $1.17 *$ & & $1.35^{* * *}$ & 1.03 & $*$ \\
\hline Stepfamily & $1.59^{* * *}$ & 1.23 & & $1.89^{* * *}$ & $1.47 *$ & \\
\hline Other & $1.55^{* * *}$ & $1.51^{* * * *}$ & & 0.96 & 1.04 & \\
\hline \multicolumn{7}{|l|}{ Religiosity parents at age 15 (ref. not religious) } \\
\hline Religious & 0.91 & 0.90 & & $0.75^{* * *}$ & 0.90 & \\
\hline Unknown & $0.74 * * *$ & 0.93 & $*$ & $0.78^{* * * *}$ & 1.00 & $*$ \\
\hline \multicolumn{7}{|l|}{ Age groups (ref. 16-20) } \\
\hline $21-25$ & $0.72^{* * *}$ & $0.76^{* * * *}$ & & $2.04 * * *$ & $6.52 * * *$ & $* * *$ \\
\hline $26-30$ & $0.35^{* * *}$ & $0.45^{* * * *}$ & & 0.78 & $6.31 * * *$ & $* * *$ \\
\hline $31-35$ & $0.04 * * *$ & $0.10^{* * *}$ & & $0.06^{* * *}$ & 1.27 & $* * *$ \\
\hline \multicolumn{7}{|l|}{ Level of education completed (ref. in education) } \\
\hline Up to lower vocational & $0.52 * * *$ & $0.57 * * *$ & & $3.60^{* * *}$ & $2.00 * * *$ & $* * *$ \\
\hline $\begin{array}{l}\text { Middle or higher secondary or middle } \\
\text { vocational }\end{array}$ & $0.85^{* *}$ & $0.75^{* * * *}$ & & $3.05^{* * *}$ & $2.04 * * *$ & $* *$ \\
\hline Higher vocational or university & $0.81 *$ & $0.81 *$ & & $1.93 * * *$ & $2.21 * * *$ & \\
\hline \multicolumn{7}{|l|}{ Cohort (ref. 1923-1939) } \\
\hline 1940-1949 & $1.41^{* * *}$ & $1.27 * *$ & & $1.70^{* * *}$ & $1.46 * * *$ & \\
\hline $1950-1959$ & $2.08 * * *$ & $1.55^{* * *}$ & $* *$ & $2.60 * * *$ & $1.42 * * *$ & $* * *$ \\
\hline $1960-1969$ & $1.70^{* * *}$ & $1.52 * * *$ & & $2.01 * * *$ & 1.16 & $* * *$ \\
\hline $1970-1980$ & $1.79^{* * *}$ & $1.82^{* * * *}$ & & $2.18^{* * *}$ & 1.16 & $* * *$ \\
\hline Immigrant or second generation immigrant & $0.79 * *$ & $1.28 * *$ & $* *$ & $0.79 *$ & 1.09 & \\
\hline \multicolumn{7}{|l|}{ Model fit } \\
\hline Number of observations in person-years & 26,485 & 24,031 & & & & \\
\hline Initial $-2 \log$ likelihood & $29,225.44$ & $22,102.32$ & & & & \\
\hline
\end{tabular}


Table 2 continued

\begin{tabular}{|c|c|c|c|c|c|c|}
\hline & \multicolumn{3}{|c|}{ Without a partner } & \multicolumn{3}{|c|}{ With partner } \\
\hline & Females & Males & Diff. & Females & Males & Diff. \\
\hline Final $-2 \log$ likelihood & $26,003.90$ & $19,733.98$ & & & & \\
\hline Prob $>\mathrm{chi}^{2}$ & 0.00 & 0.00 & & & & \\
\hline Degrees of freedom & 58 & 58 & & & & \\
\hline Pseudo $R^{2}$ & 0.11 & 0.11 & & & & \\
\hline
\end{tabular}

Source: NKPS

*** $p<0.01, * * p<0.05, * p<0.1$

partner is found only for men. However, for the interaction effect of socio-economic status of the father and age we find a statistically significant difference between men and women in the expected direction. Women are more positively affected than men are, indicating that the association of their likelihood of leaving home with their father's economic resources increases more steeply with age than men's. At older ages, parents might be more willing to use their resources in order to help their daughters find a place to live than their sons.

\subsection{The impact of family structure, atmosphere and values in the parental home}

We find clear evidence that a higher quality of the relationship between the parents has a negative effect on leaving home along both pathways, which confirms our expectations. When parents get along better, indicating a pleasant atmosphere at home, young adults stay at home longer than when their parents often have quarrels. Some effects of the number of siblings on leaving home are found. Having three or four siblings compared to not having siblings increases the likelihood of leaving the parental home to live without a partner for women. Having three or more siblings increases the likelihood of leaving home to live with a partner for men. We thus find some evidence for the suggestion that young adults are influenced by a lack of space or privacy in their parental home.

The results for family structure show the expected effects for both pathways out of the home. Women's likelihood of leaving home to live without a partner is greater when they live in a single-parent family, in a stepfamily or in other family structures. Women's likelihood of leaving home to live with a partner is also affected by living in single-parent families or stepfamilies. For men, living in single-parent families and other family structures during childhood increases the risk of leaving home to live without a partner, while living in a stepfamily also influences men's likelihood of leaving home to live with a partner. These effects are in line with our hypothesis that living in non-standard family structures leads to earlier home leaving.

We do not find any statistically significant effects of parents' being religious for the risk of leaving the parental home to live without a partner, although the odds ratios show as expected a decreased likelihood. For leaving home to live with a partner, we do find a significant effect of parental religiosity for women. However, whereas we expected to find a positive effect, the results show that women with religious parents have a smaller likelihood of leaving home to live with a partner. This may partly be caused by the fact that the category 'living with a partner' also includes cohabitation, which religious parents 
might object to. The significant parameter for women of the 'unknown' category must have something to do with selective non-response to the self-completion questionnaire.

The results point in the direction that women are affected more strongly by family structure and atmosphere than men are. We expected that women's likelihood of leaving home would be more strongly affected by living in stepfamilies, while for men a greater likelihood of home leaving was expected for living in single-parent families. For leaving home to live without a partner, the first hypothesis is confirmed, although the results for leaving home to live with a partner indicate that living in stepfamilies also increases the risk for men. Contrary to what we expected, living in a single-parent family has a stronger effect on women's likelihood than on men's. Furthermore, all parameter estimates for living in a single-parent or stepfamily are consistently greater for women than for men, even though not all differences are statistically significant. We also find a difference between men's and women's likelihood of leaving home to live without a partner for the impact of parental relationship quality, whereby the difference between low quality and medium quality is significantly greater for women than for men.

\subsection{The impact of individual characteristics}

For leaving home to live without a partner, we see that, compared to the age group 16-20, the likelihood of leaving home decreases for every older age group, which indicates that persons leaving home to live without a partner are most likely to do this when they are between 16 and 20 years old. Although women are generally found to leave home earlier than men, our results do not provide evidence that this is the case for leaving home to live without a partner. Leaving home to live with a partner is concentrated in age group 21-25 for women and in age groups 21-25 and 26-30 for men.

Compared to being enrolled in education, both females and males have a lower risk of leaving home to live without a partner when they are out of education. Once they are out of education, those with the lowest educational level have the lowest risk of leaving home to live without a partner. As in previous research, we see an increased risk of leaving home to live with a partner when being out of education for both males and females. Here we find significant gender differences. Support is found for the idea that the incompatibility of being a student and forming a union holds particularly for women. Interestingly, for those out of education, men's likelihood of leaving home to live with a partner increases with level of education, while it decreases for women. This finding seems to point to a traditional pattern in which men's resources and earning potential are of greater importance to union formation than women's (compare Oppenheimer 1988).

More recent birth cohorts have a higher risk of leaving the parental home for both pathways compared to the cohort born between 1923 and 1930. The slight decrease in later cohorts that has been found in some previous studies is not found here. In the cohort born 1950-1959, the increase in the likelihood of leaving home to live without a partner is significantly steeper for women than for men. For leaving home to live with a partner, significant gender differences are found for every cohort except the 1940-1949 cohort, indicating a greater increase in the risk of leaving home to live with a partner for females than for males. The likelihood of leaving home to live without a partner of female immigrants and second-generation immigrants differs significantly from the likelihood of male immigrants: while for women a negative effect is found, immigrant men have a higher chance of leaving home to live without a partner than native Dutch men. For leaving home to live with a partner, an effect of being an immigrant is only found for women: it decreases the odds of leaving home to live with a partner. 


\section{Conclusion and discussion}

In this paper we examined to what extent characteristics of the family of origin influence the timing of the transition of leaving the parental home for the first time and to what extent these effects differ between men and women. We distinguished between leaving home to live without a partner and leaving home for marriage or cohabitation. Gender differences were investigated by testing whether the parameters of the model for females differed significantly from the parameters of the model for males.

Our results show that both parental resources, such as the level of education of the parents and fathers' socio-economic status, and family atmosphere and structure, have a significant effect on the transition to leaving the parental home. Moreover, we found evidence that women are more influenced by several characteristics of the family of origin than men are, although parental education has a greater impact for men than for women.

Parental resources are negatively associated with leaving home at the youngest ages, but positively at higher ages. A marked gender difference is found for the influence of socioeconomic status of the father at later ages: a higher socio-economic status of the father increases women's likelihood of leaving home more than that of men. For leaving home to live with a partner, a stronger effect of parental level of education is found for men than for women. Homeownership of the parents increases the chances of women leaving home to live without a partner, but no effect is found for men. These results might indicate that parents are more willing to provide financial help to their daughters than to their sons or that women more easily accept help from their parents than men.

The atmosphere of the family of origin strongly affects the home-leaving process. A pleasant atmosphere leads to a longer stay in the parental home for both men and women. When parents have a good relationship, young adults leave home at later ages than when their parents often fight or have arguments. The effect of parental relationship quality is even stronger for women than for men. Both men and women have an increased risk of leaving home to live without a partner when living in a single-parent family, but only women leave home earlier to live without a partner when living with a stepparent. Living in a stepfamily increases both men's and women's likelihood of leaving home to live with a partner, but only women's likelihood of leaving to live with a partner is affected by living in a single-parent family.

The results suggest that a pleasant atmosphere in the parental home and the availability of transferable resources lead to a home situation in which young adults, and particularly women, feel comfortable and prefer to stay until their need for independence or their wish to form a union with a partner becomes stronger. A negative atmosphere or lack of resources, on the other hand, might push young adults out of their parental home into early cohabitation or living on their own. At later ages, apparently particularly women tend to rely on parental resources when making the transition out of the parental home.

As in previous research, we distinguished between leaving home to live without a partner and leaving home to live with a partner. This is necessary because leaving to live without a partner and leaving to live with a partner are different processes with different age patterns influenced in different ways by the various explanatory factors (most notably the young adult's enrolment in education and level of education). Although the differences between the two routes out of the parental home were not a central focus of this paper, it is remarkable that many of the effects of parental characteristics are in fact rather similar for both routes. A notable exception is the parental level of education. Those whose parents have higher vocational or university education are much more likely to leave home to live without a partner in a given year, whereas no such effect is found for leaving home to live 
with a partner. The differences between leaving home for cohabitation and leaving home for marriage might be more pronounced. This could be an interesting question for future research on different pathways out of the parental home.

Further research might focus on the question whether the effects of family background characteristics have changed across different birth cohorts and whether gender differences diminish or increase over time. We focused on leaving home for the first time. For the vast majority of young people in the Netherlands the first time is also the last-not many young people return home. Yet, it could be interesting to study the relation between parental resources and family background characteristics on returning home, though this is hardly feasible using survey data.

The NKPS data allowed us to include an indicator of the quality of the parental relationship in our models. The quality of the relationship between the young adults themselves and their parents and with their siblings could also provide information about the atmosphere at home. Specifically, information about the relationship between stepfathers and their stepchildren or single mothers with their children could give more insight into the gender differences that we have found. Regarding the issue whether parents with a high amount of parental resources indeed create a feathered nest, it could be useful also to include information on which facilities, such as an own room, parents offer their children. The actual functioning of 'Hotel Mama' is also important in this respect. Does a home situation in which parents provide cooked meals and take care of all home chores every day stimulate young adults to stay at home longer? And do boys and girls respond to this in different ways? To disentangle the specific influence of these characteristics of the parental home, further research on gender differences in the process of leaving the parental home is necessary.

Acknowledgments The research for this paper was made possible by the Netherlands Organisation for Scientific Research (NWO), VICI grant no. 453-04-001. The Netherlands Kinship Panel Study is funded by grant 480-10-009 from the Major Investments Fund of the Netherlands Organization for Scientific Research (NWO) and by the Netherlands Interdisciplinary Demographic Institute (NIDI), Utrecht University, the University of Amsterdam and Tilburg University.

Open Access This article is distributed under the terms of the Creative Commons Attribution Noncommercial License which permits any noncommercial use, distribution, and reproduction in any medium, provided the original author(s) and source are credited.

\section{References}

Aassve, A., Billari, F. C., Mazzuco, S., \& Ongaro, F. (2002). Leaving home: A comparative analysis of ECHP data. Journal of European Social Policy, 12, 259-275.

Allison, P. D. (1982). Discrete-time methods for the analysis of event histories. Sociological Methodology, 13, 61-98.

Andres, L., \& Adamuti-Trache, M. (2008). Life-course transitions, social class, and gender: A 15-year perspective of the lived lives of Canadian young adults. Journal of Youth Studies, 11, 115-145.

Aquilino, W. S. (1991). Family structure and home-leaving: A further specification of the relationship. Journal of Marriage and the Family, 53, 999-1010.

Aquilino, W. S. (1997). From adolescent to young adult: A prospective study of parent-child relations during the transition to adulthood. Journal of Marriage and the Family, 59, 670-686.

Avery, R., Goldscheider, F., \& Speare, A. (1992). Feathered nest/gilded cage: Parental income and leaving home in the transition to adulthood. Demography, 29, 375-388.

Billari, F. C., \& Liefbroer, A. C. (2007). Should I stay or should I go? The impact of age norms on leaving home. Demography, 44, 181-198.

Blau, P. M., \& Duncan, O. D. (1967). The American occupational structure. New York: Wiley. 
Blossfeld, H., \& Huinink, J. (1991). Human capital investments or norms of role transition? How women's schooling and career affect the process of family formation. American Journal of Sociology, 97, $143-168$.

Bolt, G. (2002). Turkish and Moroccan couples and their first steps on the Dutch housing market: Co-residence or independence? Journal of Housing and the Built Environment, 17, 269-292.

Buck, N., \& Scott, J. (1993). She's leaving home: But why? An analysis of young people leaving the parental home. Journal of Marriage and the Family, 55, 863-874.

Bucx, F., van der Wel, F., Knijn, T., \& Hagendoorn, L. (2008). Intergenerational contact and the life course status of young adult children. Journal of Marriage and Family, 70, 144-156.

Canada-Vicinay, J. A. (2005). Growing up in an intact vs. non-intact family and the transition from school to permanent work: A gender approach for Spain in 2000. Economics of Education Review, 24, 691-704.

Clogg, C. C., Petkova, E., \& Haritou, A. (1995). Statistical methods for comparing regression coefficients between models. American Journal of Sociology, 100, 1261-1293.

Cooney, T. M., \& Mortimer, J. T. (1999). Family structure differences in the timing of leaving home: Exploring mediating factors. Journal of Research on Adolescence, 9, 367-393.

de Jong Gierveld, J., Liefbroer, A. C., \& Beekink, E. (1991). The effect of parental resources on patterns of leaving home among young adults in the Netherlands. European Sociological Review, 7, 55-71.

de Valk, H. A. G., \& Billari, F. C. (2007). Living arrangements of migrant and Dutch young adults: The family influence disentangled. Population Studies, 61, 201-217.

de Valk, H. A. G., \& Liefbroer, A. C. (2007). Timing preferences for women's family-life. Transitions: Intergenerational transmission among migrants and Dutch. Journal of Marriage and Family, 69, 190-206.

Dykstra, P. A., Kalmijn, M., Knijn, T. C. M., Komter, A. E., Liefbroer, A. C., \& Mulder, C. H. (2005). Codebook of the Netherlands Kinship Panel Study. A multi-actor, multi-method panel study on solidarity in family relationships, wave 1. NKPS Working Paper No. 4. The Hague: Netherlands Interdisciplinary Demographic Institute.

Elder, G. H., Jr. (1994). Time, human agency, and social change: Perspectives on the life course. Social Psychology Quarterly, 57, 4-15.

Elder, G. H., Jr., Kirkpatrick Johnson, M., \& Crosnoe, R. (2003). The emergence and development of life course theory. In J. T. Mortimer \& M. J. Shanahan (Eds.), Handbook of the life course. New York: Kluwer Academic/Plenum Publishers.

Fischer, T. (2004). Parental divorce, conflict and resources. The effects on children's behaviour problems, socioeconomic attainment, and transitions in the demographic career. Nijmegen: ICS.

Furstenberg, F. F. (2008). The intersections of social class and the transition to adulthood. New Directions for Child and Adolescent Development, 119, 1-10.

Ganzeboom, H. B. G., de Graaf, P. M., \& Treiman, D. J. (1992). A standard international socio-economic index of occupational status. Social Science Research, 21, 1-56.

Goldscheider, F., \& Goldscheider, G. (1999). The changing transition to adulthood. Leaving and returning home. Thousand Oaks, CA: Sage.

Hareven, T. K. (1994). Aging and generational relations: A historical and life course perspective. Annual Review of Sociology, 20, 437-461.

Iedema, J., Becker, H. A., \& Sanders, K. (1997). Transitions to independence: A comparison of cohorts born since 1930 in the Netherlands. European Sociological Review, 13, 117-137.

Kiernan, K. E. (1992). The impact of family disruption in childhood on transitions made in young adult life. Population Studies, 46, 213-234.

Lahelma, E., \& Gordon, T. (2003). Home as a physical, social and mental space: Young people's reflections on leaving home. Journal of Youth Studies, 6, 377-390.

MacMillan, R., \& Copher, R. (2005). Families in the life course: Interdependency of roles, role configurations, and pathways. Journal of Marriage and Family, 67, 858-879.

Mitchell, B. A. (2004). Making the move: Cultural and parental influences on Canadian young adults' homeleaving decisions. Journal of Comparative Family Studies, 35, 423-441.

Mitchell, B. A., Wister, A. V., \& Burch, T. K. (1989). The family environment and leaving the parental home. Journal of Marriage and the Family, 51, 605-613.

Mulder, C. H. (2009). Leaving the parental home in young adulthood. In A. Furlong (Ed.), Handbook of youth and young adulthood. New perspectives and agendas. London: Routledge.

Mulder, C. H., Clark, W. A. V., \& Wagner, M. (2002). A comparative analysis of leaving home in the United States, the Netherlands and West Germany. Demographic Research, 7, 565-592.

Mulder, C. H., \& Hooimeijer, P. (2002). Leaving home in the Netherlands: Timing and first housing. Journal of Housing and the Built Environment, 17, 237-268.

Oppenheimer, V. K. (1988). A theory of marriage timing. American Journal of Sociology, 94, 563-591. 
Rossi, A. S., \& Rossi, P. H. (1990). Of human bonding: Parent-child relations across the life course. New York: Aldine de Gruyter.

Rusconi, A. (2004). Different pathways out of the parental home: A comparison of West Germany and Italy. Journal of Comparative Family Studies, 35, 627-649.

Weesie, J. (1999). Seemingly unrelated estimation and the cluster-adjusted sandwich estimator. Stata Technical Bulletin, 52, 34-47.

Whittington, L., \& Peters, H. E. (1996). Economic incentives for financial and residential independence. Demography, 33, 82-97. 